\title{
Measurement of pain in juvenile chronic polyarthrit
}

\author{
P. J. SCOTT, B. M. ANSELL, AND E. C. HUSKISSON \\ From The Canadian Red Cross Memorial Hospital, Taplow, and \\ Department of Rheumatology, St. Bartholomew's Hospital, London
}

SUMMARY Pain can be measured using a visual analogue scale in children with juvenile chron $\overrightarrow{\dot{j} \mathrm{t}}$ polyarthritis. In a study of 100 children failures were uncommon after the age of 5 . Pain severity wags strikingly lower than in a group of adults with rheumatoid arthritis and correlated poorly with other measures of disease severity and activity. Because of the low scores, measurement of pain is likely be less useful in children for assessing the effects of treatment than it is in adults.

Measurement of pain has proved to be particularly useful in assessing the effects of treatment in adults with rheumatoid arthritis. Visual analogue scales have been shown to be a satisfactory method of measurement with the advantage of greater sensitivity than the more conventional simple descriptive scale (Huskisson, 1974a; Scott and Huskisson, 1976). In this study the method has been applied to children with arthritis.

\section{Methods}

Pain severity was measured in 100 children with juvenile chronic polyarthritis, either inpatients or outpatients attending the Canadian Red Cross Memorial Hospital. Juvenile chronic polyarthritis was defined as polyarthritis beginning before the 16th birthday, and any patient over the age of 17 at the time of the study was excluded. A visual analogue scale without definitions or divisions was used at the same time as a 4-point simple descriptive scale; these scales were used as described by Huskisson (1974a). At the same time an independent assessment was made of the activity of the disease, based on swelling of joints and erythrocyte sedimentation rate, and severity of the disease, based on the number and severity of joints involved and functional status. Both were graded on a 4-point scale.

\section{Results}

The age distribution of the children is shown in Fig. 1, divided according to whether or not they were able to complete a visual analogue pain scale. $11 \%$ failed

Accepted for publication June 14, 1976

Correspondence to Dr. E. C. Huskisson, Dept. of Rheumatology, St Bartholomew's Hospital, West Smithfield, London EC1A 7BE

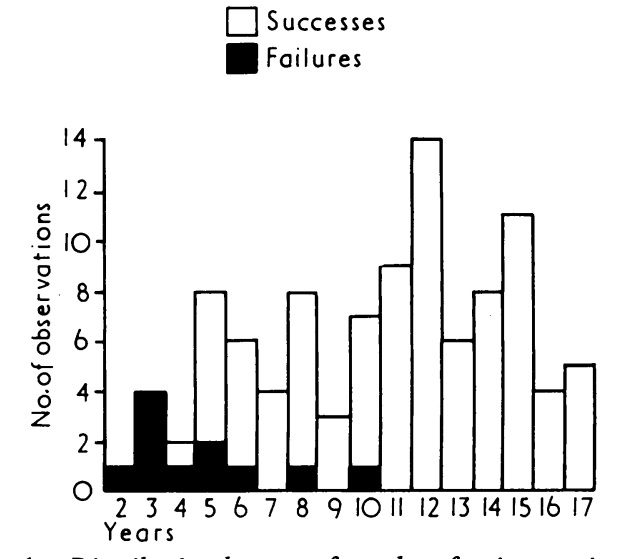

Fig. 1 Distribution by age of results of pain severity measurement using a visual analogue scale, showing successes and failures.

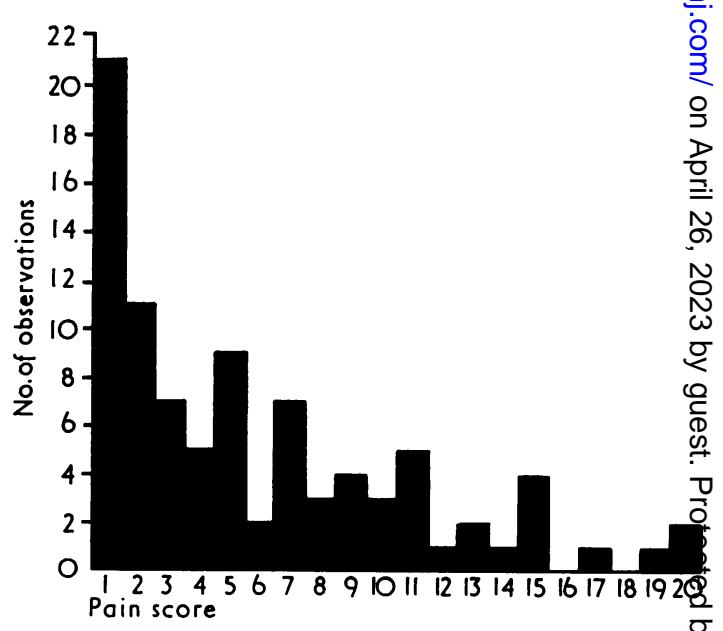

Fig. 2 Distribution of pain scores in children with juvenile chronic polyarthritis. 
to complete the scale, and this was particularly common below the age of 5. Figs. 2 and 3 show the distribution of pain scores on a visual analogue scale in children and in 100 consecutive adults. Whereas the distribution in adults was approximately uniform, pain scores in children were predominantly low.

There was a highly significant correlation between pain severity measured on visual analogue and simple descriptive scales $(r=0.63 ; \mathrm{P}<0.01)$. There was no significant correlation between the visual analogue pain score and age, activity, or severity scores $(r=0 \cdot 12,0 \cdot 2$, and $0 \cdot 2$ respectively).

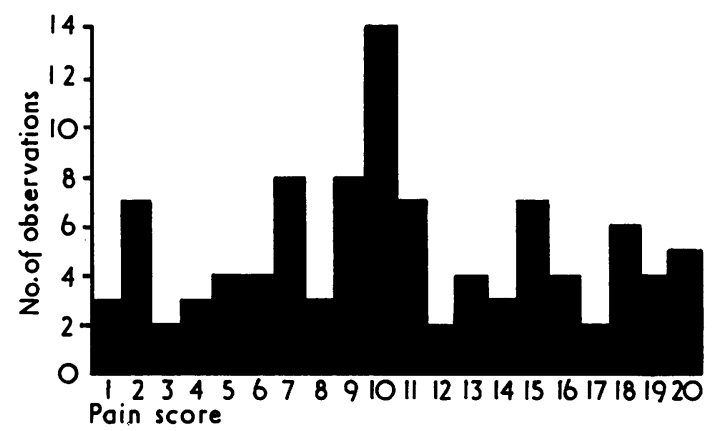

Fig. 3 Distribution of pain scores in adults with rheumatoid arthritis.

\section{Discussion}

The predominance of low pain scores found in children with juvenile chronic polyarthritis is in accord with previous experience that pain is not a prominent feature of the symptomatology of this disease (Laaksonen and Laine, 1961). Pain can be measured in most children and few of those over the age of 5 had any difficulty in understanding the concept of the visual analogue scale. However, pain is not a particularly useful measurement for clinical trials in children because most scores are low and there is therefore little potential for improvement.

Whereas pain severity in adults has been reported to correlate well with other measures of disease severity (Huskisson, 1974b), it appears that the severity of pain in children is not a good indication either of the severity or the activity of the disease process. This is another reason for questioning the value of pain measurement in clinical trials in children. The failure rate of $11 \%$ is a little higher than the $7 \%$ reported by Huskisson (1974a) for the use of a visual analogue scale in adults. After the age of 5 , it seems that failures are as unusual in children as they are in adults.

It is difficult to explain the finding of low pain scores in children with arthritis. Pain threshold rises with age and does not therefore appear to be a factor. It may be that the sensation of pain requires learning or maturation (Merskey, 1975) and it is a common observation that children may sustain considerable trauma with minimal pain. Parental attitude may also be important and on some occasions we noted a striking discrepancy between pain severity assessed separately by parent and child. Some children were encouraged by their parents to give higher pain scores than they had originally indicated.

\section{References}

Huskisson, E. C. (1974a). Measurement of pain. Lancet, 2, 1127-1131.

Huskisson, E. C. (1974b). Measurement of pain and pain threshold in patients with arthritis. M.D. thesis, London University.

Laaksonen, A. L., and Laine, V. (1961). A comparative study of joint pain in adult and juvenile rheumatoid arthritis. Annals of the Rheumatic Diseases, 20, 386-387.

Merskey, H. (1975). Pain, learning and memory. Journal of Psychosomatic Research, 19, 319-324.

Scott, P. J., and Huskisson, E. C. (1976). Graphic representation of pain. Pain, 2, 175-184. 